March - 2010

\title{
The Role of Volition in Distance Education: An Exploration of its Capacities ${ }^{1}$
}

\author{
Markus Deimann and Theo Bastiaens \\ FernUniversität in Hagen, Germany
}

\begin{abstract}
During the past two decades, volition, defined as the ability to stay task-focused and ward off distractions, has become of special relevance for educational research and practice. It describes how decreased motivation or negative emotions can be dealt with by applying action control strategies. However, despite its potential, an important area of education has neglected volitional considerations: distance education (DE). This seems paradoxical because by its very nature distance education requires a great deal of persistence and effort that is volitional. Consequently, the present paper introduces a conceptual framework built on volitional theories; it aims to augment traditional perspectives and to analyse major challenges to DE, such as dropout rates.
\end{abstract}

The paper reports results from a longitudinal study (September 2007-July 2009) that was conducted to determine the factorial structure of the Volitional Persona Test (VPT), an online instrument to assess volitional competence, and to obtain detailed information on students' volitional competence at a large $\mathrm{DE}$ university and at numerous traditional universities in German-speaking countries. It was demonstrated that the construct of volition can be subdivided into distinct factors, volitional self-efficacy, consequence control, emotion control, and metacognition, which enables the development of support systems that are tailored to learners' individual needs. Implications for future research are discussed.

Keywords: Distance education, learner support

\section{Motivation in Distance Education}

Distance education has emerged as a significant trend in our ever-changing, knowledge-based society. It is a flexible way of studying as it allows learners to pursue goals from different areas (e.g., family, job) simultaneously.

\footnotetext{
${ }^{1}$ An earlier version of this paper was presented at the 2009 AERA Annual Meeting, "Disciplined Inquiry: Education Research in the Circle of Knowledge", San Diego, CA.
} 
Despite considerable changes over the past decades, DE is still viewed as a set of defining elements. Among them are the separation of teacher and learner during most of the instructional process and the use of educational media to bridge this separation (Keegan, 1996).

These two elements contribute to a form of learning that is radically different from traditional learning because the learner is fully in charge of her/his learning process. In this autonomous, self-regulated learning environment, individuals are assumed to be capable of planning, organizing, controlling, and evaluating their work (Peters, 2002). In this regard, motivation is a key issue as it enables the learner to master various challenges and to attain his/her goals. As a result, researchers have paid some attention to the role of motivation in DE.

\section{Literature Review}

There have been several lines of research on motivation in DE, which will be reported in this section. One line pertains to motivation as a personal characteristic for DE learning that is conceptualized as a relatively stable trait and is reported to play a crucial role (Gao \& Lehman, 2003; Holder, 2007; Hurd, 2006; Sankaran \& Bui, 2001; Wang, Peng, Huang, Hou, \& Wang, 2008). Moreover, Martens, Bastiaens, and Kirschner (2007) found that in addition to DE learners, DE developers attach a high value to motivation. Whereas these studies have covered motivation on a general level, Wang, Peng, Huang, Hou, and Wang (2008) revealed motivational variables, self-efficacy and internal attributions, to be positively and predictably related to learning results.

Another line of research attempts to build a holistic approach, for instance to utilize motivation theory for DE learning. Liao (2006) proposes such an example by drawing on flow theory (Csikszentmihalyi, 1975) in order to provide a useful framework for studying the individual differences of DE learners. Song (2000) presents a collection of research issues related to motivation in DE and distinguishes between three stages, (1) motivation to initiate, (2) motivation to persist, and (3) motivation to continue, which may allow DE instructors to address problems that occur at each stage. In a similar vein, Garrison (1997) suggests a comprehensive model to capture the major dimensions of self-directed learning: (1) self-management (task control), (2) self-monitoring (cognitive responsibility), and (3) motivation (entering and task). The latter element is defined as the process of deciding to participate, such as entering a DE program, and the effort needed to stay on task and persist. Furthermore, emphasis is placed on the fact that much can happen during the learning process, so motivation and persistence are subject to fluctuations.

Finally, there is a line of study that draws on motivation concepts and models for the purpose of equipping learners with strategies that can be adopted while learning in a DE environment. Tuckman (2007) employed a so-called motivational scaffold to minimize procrastination among distance learners. It includes study skills support groups, to-do-checklists, and chat sessions. Results showed that procrastinators performed better in the motivationally scaffolded condition while non-procrastinators performed equally in the experimental and in the control condition.

L. Visser, Plomp, Amirault, and Kuiper (2002) conducted a study to test the effectiveness of motivational strategies that should serve to help DE students to become or to stay motivated. A 
motivational messages support system (MMSS) was designed and developed based on Keller's (1983) ARCS model of motivational design and on previous work by J. Visser and Keller (1990). Findings indicated that the messages were effective (e.g., improved retention rates) and appreciated by students. Recently, Wickramanayake, Schlosser, and Deimann (2008) have used a similar approach in a comparative study to test the effectiveness of email vs. SMS. ChanLin (2009) has also drawn on the ARCS model to create a motivating interaction environment in a web-based course.

Despite these different lines of research on motivation, there are some gaps and shortcomings that need to be addressed.

\section{Shortcomings in the Study of Motivation}

As shown above, theoretical conceptualizations and empirical studies have described motivation as a very powerful force that determines whether learning goals will be attained. However, motivation does not fully explain human action. In particular, when obstacles and distractions arise during the learning process, motivational support may not be strong enough to tackle problems. In these cases, an additional variable is required, specifically targeted at overcoming motivational fluctuations: volition, which is defined as "... the tendency to maintain focus and effort toward goals despite potential distractions" (Corno, 1994, p.229). Whereas motivation initiates and directs action, volition maintains a course of action when obstacles arise. The distinct nature of volition has been illustrated by a muscle or an emergency backup generator, which comes into play when the primary source of energy, motivation, loses strength.

Volition is important for learning at a distance. A DE learner is challenged by multiple and conflicting responsibilities (e.g., family, job), which may endanger his/her motivation to learn. In order to manage decreased motivation, volitional strategies, such as controlling negative emotions triggered by a heavy workload or by family stress, can be applied.

Unfortunately, until now DE research has focused exclusively on motivational aspects of learning; whereas, the actual phase that involves the use of volitional strategies has been neglected. Thus, what DE learners do when obstacles, such as role conflicts, arise has not been investigated. How do they control their emotions after an experience of failure? How do they invest persistence after a hard-working day and after taking care of the family? These are some exemplary questions that can be scrutinized through the lense of volitional theories.

Not only can researchers benefit from an understanding of this relatively unknown body of work, so can practitioners. Based on a profound theoretical framework, strategies that are targeted at overcoming the typical problems of DE learners can be derived. The next section introduces such a theoretical framework and discusses its importance for DE. 


\section{An Integrative Framework of Motivation, Volition, and Distance Education}

As Lee, Driscoll, and Nelson (2007) concluded, based on a content analysis of major journals in $\mathrm{DE}$, there is a strong need for more theory-based studies, including attempts that describe how an unique theory can support DE. Moreover, Anderson (2004) criticizes that DE research has not yet made clear the affective components of the learner and has left out critical components, such as volition.

The relative complexity of volitional control processes can be reduced by referring to the metaphor of "will as a steersman" (Keller \& Deimann, in press), which is based on major theoretical models, such as action control theory (Kuhl, 1985), attention to action (Norman \& Shallice, 1986), and on more recent conceptions, such as the meta-model of volition (Sniehotta, Scholz, \& Schwarzer, 2005) as well as the compensatory model of motivation and volition (Kehr, 2004).

The will as a steersman metaphor describes the balance of learners' motivational, cognitive, and emotional processes with the overall goal to navigate safely through rough courses of action. The instruments that are helpful for these tasks have been described as action control strategies (Kuhl, 1985) and contain the following:

1. Selective attention: also called the "protective function of volition" (Kuhl, 1984, p.126), which shields the current intention by inhibiting the processing of information about competing action tendencies;

2. Encoding control: facilitates the protective function of volition by selectively encoding those features of incoming stimulus that are related to the current intention and ignoring irrelevant features;

3. Emotion control: managing emotional states to allow those that support the current intention and suppress those, such as sadness, in regard to a competing intention that might undermine it;

4. Motivation control: maintaining and reestablishing saliency of the current intention, especially when the strength of the original tendency is not strong ("I must do this even though I don't really want to.");

5. Environment control: Creating an environment that is free of uncontrollable distractions and making social commitments, such as telling people what you plan to do, which help to protect the current intention;

6. Parsimonious information processing: Knowing when to stop, making judgments about how much information is enough, and making decisions that maintain active behaviors to support the current intentions.

The effectiveness of utilizing action control strategies has been confirmed in many studies in a variety of behavioral change settings (Kuhl, 1987) as well as in educational settings (Corno, 2001; Zimmerman, 2001). Although action control strategies seem to be highly relevant for DE, 
little has been done in this area so far. The following section outlines the potential and benefits of volition and action control strategies in critical DE situations.

\section{Benefits of Volition and Action Control Strategies}

\section{Delay of Gratification}

This phenomenon refers to individuals' intentions to postpone immediate available rewards in order to obtain larger rewards temporally distant (Bembenutty \& Karabenick, 1998). Obtaining a degree in DE requires balancing several, oftentimes conflicting responsibilities (e.g., taking care of family members, meeting friends) over an extended period of time. In particular, admonishing oneself to study on the weekend or during evening hours can be challenging when family members or friends make social demands that provide immediate reward (e.g., emotional wellbeing). To focus on the learning assignment can thus be associated with less positive feelings and requires acts of willpower. In these cases, the volitional strategy of emotion control can be beneficial as it helps the person to reassure himself/herself when experiencing feelings of boredom (Brophy, 2004). There is empirical evidence indicating that the use of volitional strategies is related to decreased delay of gratification, increased effort, and better time and study management (Bembenutty, Karabenick, McKeachie, \& Lin, 1998).

\section{Dropout Rates}

Along with the growth of $\mathrm{DE}$, there has been the problem of high dropout rates, sometimes as high as $40 \%$ (Carter, 1996). Consequently, research has focused heavily on factors that may affect attrition, such as mentoring (Bernard \& Amundsen, 1989; Garrison, 1987; Tinto, 1975), and it has revealed persistence as an important factor (Levy, 2007). As mentioned, DE studies have neglected volition as a key determinant of persistence and goal-oriented learning. Pintrich (1999) has conceptualized the control of effort and persistence as a volitional strategy located at the construct "control of behaviour." For instance, it can be utilized by way of self-talk: "I just need to stay with it a little more." This can be easily adapted to DE so that learners can enhance their willingness to complete their learning tasks. There are further strategies to control motivation and to avoid premature skipping of the task, such as interest enhancement (e.g., trying to make the task more appealing). DE institutions should equip novice students with such strategies, for instance in workshops, to sensitize them to and prepare them for potential problems that might arise during the semester. As has become clear from research on effort and persistence, the best predictor of learners acting volitionally is conditional knowledge (Boekaerts, 2006; Kuhl \& Kraska, 1989), which means that students' knowledge about potential obstacles to goal-pursuit and the way to deal with them effectively predict the degree of effort to invest in the task. Thus, it is important to make students aware of strategies that can help them to increase or decrease effort when needed. This refers to learners' volitional competence, which will be a central topic later in this paper. 


\section{Role Conflicts}

Learning at a distance is perceived as a convenient form of expanding one's knowledge and of enhancing promotion prospects as most of the time the learner does not need to be on campus. Instead he/she can combine working at home and taking care of the children or other family members with job obligations. However, this can lead to role-conflicts and related stress, especially for female students (Home, 1998). It is crucial to be able to set adequate priorities so that role responsibilities do not interfere with learning goals. More specifically, volitional strategies, such as control of time use or control of others in the task setting, can be utilized in order to reduce possible role-conflicts. As specified by Corno and Kanfer (1993), those strategies are targeted at monitoring and regulating important aspects of the learning process. If, for instance, a DE learner is having trouble with his/her children and/or other family members while trying to learn, he/she can ask them to be quiet. Another possibility would be to arrange special hours in which every family member is told that "mum" or "dad" wants to be alone in order to progress with the learning materials.

\section{Need to Assess Volitional Competence in DE}

The aforementioned scenarios have stressed the fact that it is legitimate to assume that DE learners may be unaware of volitional strategies since they have been temporarily away from formal, academic settings (Semmar, 2006). Moreover, they may not have had the opportunity to investigate or assess their competences to deal with conflicting roles or to face distractions, which may result in decreased motivation. Research has provided evidence that when learners have to work within an unfamiliar context (e.g., a web-based setting), many of them are concerned about their ability to manage technical, organizational, and social challenges (Whipp \& Chiarelli, 2004). Moreover, an inadequate appraisal of one's volitional skills can be related to an overestimation of one's abilities (Kruger \& Dunning, 1999). Wolters (2003) reports that learners who used volitional strategies less frequently seemed to procrastinate more often than students who used them more frequently. It is therefore important to make students aware of their capabilities to effectively apply volitional strategies in a specific context (Boekaerts, 2006). By doing so, learners can enhance their ability to regulate and monitor their study behaviors across various tasks, and this may lead to more realistic self-appraisals concerning one's weaknesses and strengths and to less procrastination (Thiede, Anderson, \& Therriault, 2003).

This was the goal of a developmental project at the FernUniversität in Hagen, which included an online questionnaire to assess learners' volitional competence. It investigated to what extent DE learners utilize volitional strategies.

\section{Investigating Volitional Competence in DE}

In order to gain insight into the volitional actions of DE learners, an online questionnaire, labeled Volitional Persona Test (VPT), was developed (Deimann, Weber, \& Bastiaens, 2009). It is based on two validated instruments, the Volitional Components Inventory (VCI, Kuhl, \& Fuhrmann, 
1998) and the Academic Volitional Strategy Inventory (AVSI, McCann \& Turner, 2004). Both provide insight into different aspects of volitional control (e.g., stress-reducing actions). However, they are not particularly tailored to distance education. Therefore, several semistructured interviews with distance learners at the FernUniversität in Hagen were conducted to identify relevant situations and strategies that could then be prepared as items. This led to 32 items, which describe volition-eliciting situations and cover a broad range of volitional strategies (for an overview, see Pintrich, 1999).

After the participant answers the final question, the VPT immediately provides an individual competence profile illustrated by a traffic light. This means that if the level of a certain volitional competence falls below a critical value, the respective traffic light turns red to indicate a gap. In the opposite case, if the level exceeds a critical value, the light shows orange to refer to a potentially excessive use of volitional control. As previous research has shown, this may cause serious problems, such as depression (Kuhl \& Helle, 1986); therefore, the importance of finding a balanced state of learning is accentuated. If the value is within an optimal range, the light turns green. However, the VPT not only gives a detailed analysis, it also suggests strategies based on the individual's profile. The pool of strategies has been compiled based on an extensive literature review (Corno, 2001; Gollwitzer, 1999; Kuhl, 1985; Locke \& Latham, 2002). Thus, the learner is given the opportunity to bridge volitional gaps and to optimize the learning process.

\section{Subjects and Procedure}

There were 15,559 participants recruited by direct communication (email to the students of the FernUniversität in Hagen) or by indirect communication (various articles in newspapers, magazines, online portals, blogs etc.). In order to control the response behavior of the participants, several control measures were applied. One of them was the high-hurdle technique (Göritz \& Stieger, 2008), which attempts to filter out less motivated individuals through high response burden. In this regard, the VPT entails a lengthy introduction and a great deal of background information as well as two control items (negation, doubling).

By doing so, a large number of German-speaking campus-based universities, universities of applied science, and high schools (in addition to the FernUniversität) could be reached: From the FernUniversität in Hagen, there were 2512 males (34\%), 4863 females (66\%), Ø age 34 (SD 9.0); from the campus-based universities, there were 2726 males (49\%), 2799 females (51\%), $\varnothing$ age 28 (SD 9.2); from the universities of applied science, there were 1108 males (58\%), 795 females (42\%), $\varnothing$ age 28 (SD 8.7); from the high schools, there were 333 males (44\%), 416 females (56\%), Ø age 20.7 (including teachers) (SD 11.7).

\section{Results and Discussion}

This section reports results from a longitudinal study (September 2007-July 2009) that was conducted to determine the factorial structure of the VPT and to obtain detailed information on students' volitional competence at a large DE university and at numerous traditional universities 
in German-speaking countries. The research builds on an explanatory approach, which is part of a long-term project at the FernUniversität in Hagen.

\section{Factor Analysis}

A confirmatory factor analysis with 13,364 subjects based on the outlined theoretical foundation (Kehr, 2004; Kuhl \& Fuhrmann, 1998; Sniehotta, Scholz, \& Schwarzer, 2005) was calculated. In contrast to the three-factorial structure of the Academic Volitional Strategy Inventory (McCann \& Turner, 2004) - self-efficacy enhancement, negative-based incentives, and stress-reducing actions - a four-factorial solution with an explained $41 \%$ of the total variance was revealed: factor 1 , volitional self-efficacy (18\%); factor 2, consequence control (11\%); factor 3, emotion control (7\%), factor 4, meta-cognition (4\%). A high percentage of variance could be explained by the fact that the study was conducted online and could not control typical conditions in experiments (Rhodes, Bowie, \& Hergenrather, 2003).

The first factor contains eight items, classified as volitional self-efficacy. In contrast to Bandura's well-known concept of self-efficacy (1997), which is focused on motivational (i.e., pre-actional aspects), volitional self-efficacy represents a postintentional construct assumed to be crucial for engagement in planning and for change in behavior (Schwarzer, 2008). The second factor contains six items, loading on the construct of consequence control, which can be described by the question, "What will happen if I fail with my action?" and can be used to counter decreased motivation. Consequence control is related to the concept of "failure control" (Kuhl \& Fuhrmann, 1998, p. 23), which focuses on the correction of failure; further, the emotion caused by the failure (disappointment, anger) is employed toward the mobilization of effort. The third factor contains six items, loading on the construct of emotion control, which enhances positive emotions (e.g., thinking of joyful things) and controls negative emotions (e.g., by applying breath techniques). The last factor contains nine items, focusing on meta-cognition, such as careful planning or time management.

Taken together, the factorial structure could confirm the theoretical postulations. Volitional action can be subdivided into distinct factors that are responsible for regulating major aspects of the self, such as achieving a positive emotional state. Table 1 shows the factors with their factor loading, the number of items, and Cronbach's alpha values. 
Table 1

Results of the Confirmatory Factor Analysis

\begin{tabular}{|c|c|c|c|}
\hline Volitional competency & $\begin{array}{l}\text { Factor } \\
\text { loading }\end{array}$ & $\mathrm{N}$ & $\alpha$ \\
\hline Volitional self-efficacy & 5,9 & 8 & .79 \\
\hline $\begin{array}{l}\text { e.g., reflecting one's strength to master the task } \\
\text { Consequence control } \\
\text { e.g., reflecting on consequences when the task will not be successfully } \\
\text { finished }\end{array}$ & 3,4 & 6 & .80 \\
\hline $\begin{array}{l}\text { Emotion control } \\
\text { e.g., thinking of joyful things }\end{array}$ & 2,1 & 6 & .64 \\
\hline $\begin{array}{l}\text { Meta-cognition } \\
\text { e.g., deliberate planning of the task }\end{array}$ & 1,4 & 9 & .71 \\
\hline
\end{tabular}

\section{Differences in Volitional Competency among Educational Institutions}

Mean volitional competency scores for learners at the FernUniversität in Hagen (FU), campusbased universities (CBU), universities of applied science (UAS), and high schools (HS) are displayed in Table 2.

An ANOVA with four factors (volitional self-efficacy, consequence control, emotion control, and meta-cognition) as dependent variables and the type of institution as the independent variable was calculated to detect differences in the degree of volitional competency. The results revealed significant differences between the educational institutions. However, the effect sizes are very small due to the large population size.

Table 2

Results of the ANOVA

\begin{tabular}{|c|c|c|c|c|c|c|c|}
\hline Questionnaire scale & & $\begin{array}{l}\mathrm{FU} \\
\mathrm{N}=7380\end{array}$ & $\begin{array}{l}\text { CBU } \\
\mathrm{N}=5114\end{array}$ & $\begin{array}{l}\text { UAS } \\
N=561\end{array}$ & $\begin{array}{l}\mathrm{HS} \\
\mathrm{N}=309\end{array}$ & $\mathrm{p}$ & $\mathrm{d}$ \\
\hline Volitional self-efficacy & $\mathrm{M}(\mathrm{SD})$ & $3.39(.66)$ & $\begin{array}{l}3.09 \\
(.70)\end{array}$ & $\begin{array}{l}3.22 \\
(.70)\end{array}$ & $\begin{array}{l}3.36 \\
(.72)\end{array}$ & $<.05 * * *$ & .04 \\
\hline Consequence control & $\mathrm{M}(\mathrm{SD})$ & $3.52(.76)$ & $\begin{array}{l}3.58 \\
(.75)\end{array}$ & $\begin{array}{l}3.60 \\
(.73)\end{array}$ & $\begin{array}{l}3.61 \\
(.80)\end{array}$ & $<.05 * * *$ & .00 \\
\hline Emotion control & $\mathrm{M}(\mathrm{SD})$ & $2.80(.73)$ & $\begin{array}{l}3.08 \\
(.70)\end{array}$ & $\begin{array}{l}3.10 \\
(.71)\end{array}$ & $\begin{array}{l}3.13 \\
(.72)\end{array}$ & $<.05 * * *$ & .04 \\
\hline Meta-cognition & M (SD) & $2.99(.61)$ & $\begin{array}{l}2.87 \\
(.61)\end{array}$ & $\begin{array}{l}2.88 \\
(.62)\end{array}$ & $\begin{array}{l}2.90 \\
(.66)\end{array}$ & $<.05^{* * *}$ & .01 \\
\hline
\end{tabular}

An interesting pattern is worth mentioning: DE students show higher volitional self-efficacy and lower emotion control compared to campus-based learners. This is in line with recent research 
demonstrating that negative emotions and motivational challenges may be evoked when learners work face-to-face in groups (Järvenoja \& Järvelä, 2009). In contrast, DE students typically learn independently and thus may not experience as often those situations of motivational and emotional challenge. However, as indicated by a high VSE, they seem to be able to mobilize more effort towards goal attainment when needed. DE is often part of a long-term and life-long goal, and apparently DE learners are willing to invest many personal resources.

\section{General Discussion}

The present study gives insight into the functional complexity of volition within an educational field of growing importance. Based on an extensive literature review, an online questionnaire to capture volitional competency was developed and tested empirically. The dissemination took place in a naturalistic setting in which participants could decide when and where to fill out the questionnaire. A confirmatory factor analysis revealed consensus with the theoretical assumptions. The reliability of each scale indicated moderate to high levels of internal consistency. Although the ANOVA calculation yielded significant but not very strong mean differences, some tentative conclusions can be drawn.

An interesting pattern that emerged was that learners at the FernUniversität scored highest both in volitional self-efficacy and in meta-cognition and lowest in emotion control. Previous research has shown that meta-cognitive aspects, such as the ability to develop a personal learning plan, are important aspects of learner autonomy in DE (Chen \& Willits, 1999). The high amount of volitional self-efficacy implies that it is crucial to have the belief that in the case of learning problems (i.e., failure to stick to the plan), volitional strategies can be utilized. On the other hand, the relatively low degree of emotion control points out a crucial issue. Several studies have shown that insufficient affective and emotional support is related to decreased motivation and eventually to dropout (Gibson, 1996). It is therefore important to equip DE learners with strategies that help them to overcome fears (e.g., feeling separated from the instructor). A first step in this direction is to check various aspects of the learning environment (e.g., study materials) regarding their emotional quality. Astleitner's (2000) F(ear), E(envy), A(anger), S(ympathy), P(leasure) approach is useful for this purpose. It entails detailed prescriptions on how to enhance positive emotions and how to minimize the influence of negative emotions.

The present study has some limitations. Since the distribution of the VPT was not in an experimental setting, it remains unclear how the participants actually used the questionnaire. Yet, the relatively high sample (approximately 25,000 as of August 2007) indicates that there may have been some valuable aspects generated by utilizing the test.

\section{Conclusions}

The present research sheds light on a critical issue that has been left uninvestigated in prior DE research: volition, or the ability to be continuously motivated throughout learning activities. It has been argued that there has been some research on motivational issues, such as the concept of flow (Liao, 2006). However, motivation does not fully account for the entire learning process. Instead 
it focuses on pre-actional processes and does not deal with problems that may occur after the action has been initiated.

The unique approach of DE requires a special form of learning, which has been referred to as autonomous, self-regulated learning (Peters, 2002). Learners are assumed to take responsibility for their learning activities (e.g., careful planning). In addition, learners are faced with multiple and conflicting roles, such as taking care of family members or job obligations. All these issues challenge learners' motivation, meaning that a high motivation at the beginning can be jeopardized and lead to impairments of performance. In this regard, volitional theories and models provide a profound base of explanations about how to foster goal-oriented learning by addressing decreased motivation.

Major concepts of volition, such as the theory of action control (Kuhl, 1984), have been introduced recently to educational research (Corno, 2001) and have outlined potential benefits. However, such an approach has been missing in the context of DE. Thus, the present paper presented a conceptional framework, targeted at explaining specific issues, such as the delay of gratification.

A further concern of the presented approach was to stress the importance of assessing one's volitional competence. Hence, an online questionnaire, the Volitional Persona Test (VPT) (Deimann, Weber, \& Bastiaens, 2009), was introduced. First empirical data were presented and discussed with regard to distinctions between a DE university and traditional institutions. It was demonstrated that the global construct of volition can be subdivided into distinct factors, representing unique aspects of human self-regulation. This allows developing support systems that are tailored to learners' individual needs.

The overall significance of the study rested on the broad dissemination of the VPT so that the vast majority of German-speaking universities could be reached. Based on a combined approach of direct and indirect communication, over 25,000 datasets were gathered.

Yet much more research needs to be conducted to further reveal the potential of volitional concepts for DE. For instance it would be interesting to analyze volitional behaviour within problematic learning episodes, such as procrastination. Also, exemplary role conflicts could be identified and analysed in terms of volitional principles.

It is hoped that this paper will arouse interest in other researchers. 


\section{References}

Anderson, T. (2004). A second look at learning sciences, classroom, and technology: Issues of implementation: Making it work in the real world. In T. M. Duffy \& J. R. Kirkley (Eds.), Learner-centered theory and practice in distance education (pp. 235-249). Mahwah, NJ: Erlbaum.

Astleitner, H. (2000). Designing emotionally sound instruction: The FEASP-approach. Instructional Science, 28, 169-198.

Bandura, A. (1997). Self-efficacy: The exercise of control. New York: Freeman.

Bembenutty, H., \& Karabenick, S. A. (1998). Academic delay of gratification. Learning and Individual Differences, 10(4), 329-346.

Bembenutty, H., Karabenick, S. A., McKeachie, W., \& Lin, Y.-G. (1998). Academic delay of gratification as a volitional strategy. Paper presented at the Annual Meeting of the American Educational Research Association, San Diego, CA.

Bernard, R. M., \& Amundsen, C. L. (1989). Antecedents to dropout in distance education: Does one model fit all? Journal of Distance Education, 4(2), 25-46.

Boekaerts, M. (2006). Self-regulation and effort investment. In K. A. Renninger, I. E. Sigel, W. Damon \& R. M. Lerner (Eds.), Handbook of child psychology: Vol 4. Child psychology in practice (pp. 345-377). New York: Wiley.

Brophy, J. (2004). Motivating students to learn. London: Routledge.

Carter, V. (1996). Do media influence learning? Revisiting the debate in the context of distance education. Open Learning, 11(1), 31-40.

Chen, Y.-J., \& Willits, F. K. (1999). Dimensions of educational transactions in a videoconferencing learning environment. American Journal of Distance Education, 13(1), 45-59.

Corno, L. (1994). Student volition and education: Outcomes, influences and practices. In D. H. Schunk \& B. J. Zimmermann (Eds.), Self-regulation of learning and performance. Issues and educational applications (pp. 229-254). Hilsdale, NJ: Erlbaum.

Corno, L. (2001). Volitional aspects of self-regulated learning. In B. J. Zimmerman \& D. H. Schunk (Eds.), Self-regulated learning and academic achievement. Theoretical perspectives (pp. 191-226). Mahwah, NJ: Erlbaum. 
Corno, L., \& Kanfer, R. (1993). The role of volition in learning and performance. Review of Research in Education, 19, 301-341.

Cropley, A. J., \& Kahl, T. N. (1983). Distance education and distance learning: Some psychological considerations. Distance Education, 4(1), 27-39.

Csikszentmihalyi, M. (1975). Beyond boredom and anxiety. San Francisco: Jossey-Bass.

Deimann, M., Weber, B., \& Bastiaens, T. (2009). Entwicklung und Verbreitung eines Tests zur Analyse der Willensstärke in Schule und Hochschule [Development of a test of volitional competence in schools and universities]. Unterrichtswissenschaft, 37(4), 362-379.

Gao, T., \& Lehman, J. D. (2003). The effects of different levels of interaction on the achievement and motivational perceptions of college students in a Web-based learning environment Journal of Interactive Learning Research, 14(4), 367-386.

Garrison, D. R. (1987). Resarching dropout in distance education. Distance Education, 8(1), 95101.

Garrison, D. R. (1997). Self-directed learning: Toward a comprehensive model. Adult Education Quarterly, 48(1), 18-33.

Gibson, C. C. (1996). Toward an understanding of academic self-concept in distance education. American Journal of Distance Education, 10(1), 23-36.

Göritz, A. S., \& Stieger, S. (2008). The high-hurdle technique put to the test: Failure to find evidence that increasing loading times enhances data quality in Web-based studies. Behavior Research Methods, 40(1), 322-327.

Holder, B. (2007). An investigation of hope, academics, environment, and motivation as predictors of persistence in higher education online programs. Internet and Higher Education, 10(4), 245-260.

Home, A. M. (1998). Predicting role conflict, overload, and contagion in adult women university students with families and jobs. Adult Education Quarterly, 48(2), 85-97.

Hurd, S. (2006). Towards a better understanding of the dynamic role of distance language learner: Learner perceptions of personality, motivation, roles, and approaches. Distance Education, 27(3), 303-329.

Järvenoja, H., \& Järvelä, S. (2009). Emotion control in collaborative learning situations: Do students regulate emotions evoked by social challenges? British Journal of Educational Psychology, 79, 463-481. 
Keegan, D. J. (1996). Foundations of distance education. London: Routledge.

Kehr, H. M. (2004). Implicit/explicit motive discrepancies and volitional depletion among managers. Personality and Social Psychology Bulletin, 30, 315-327.

Keller, J. M., \& Deimann, M. (in press). Motivation, volition, and performance. In R. Reiser \& J. V. Dempsey (Eds.), Trends and issues in instructional design and technology. Upper Saddle River: Prentice Hall.

Kruger, J., \& Dunning, D. (1999). Unskilled and unaware of it: How difficulties in recognizing one's own incompetence lead to inflated self-assessments. Journal of Personality and Social Psychology, 77(6), 1121-1134.

Kuhl, J. (1984). Volitional aspects of achievement motivation and learned helplessness: Toward a comprehensive theory of action control. In B. A. Maher \& W. B. Maher (Eds.), Progress in experimental personality research (pp. 101-171). Orlando: Academic Press.

Kuhl, J. (1985). Volitional mediators of cognitive-behavior-consistency: Self-regulatory processes and action versus state orientation. In J. Kuhl \& J. Beckmann (Eds.), Action control: From cognition to behavior (pp. 101-128). Berlin: Springer.

Kuhl, J., \& Fuhrmann, A. (1998). Decomposing self-regulation and self-control: The volitional components inventory. In J. Heckhausen \& C. S. Dweck (Eds.), Motivation and selfregulation across the life span (pp. 15-49). Cambridge: Cambridge University Press.

Kuhl, J., \& Kraska, K. (1989). Self-regulation and metamotivation: Computational mechanism, development and assessment. In R. Kanfer, P. L. Ackermann \& R. Cudeck (Eds.), Abilities, motivation and methodology. The Minnesota Symposium on Learning and Individual Differences (pp. 343-374). Hillsdale, NJ: Erlbaum.

Lee, Y., Driscoll, M. P., \& Nelson, D. W. (2007). Trends in research: A content analysis of major journals. In M. G. Moore (Ed.), Handbook of distance education (pp. 31-41). Mahwah, NJ: Erlbaum.

Levy, Y. (2007). Comparing dropouts and persistence in e-learning courses. Computers \& Education, 48(2), 185-204.

Liao, L.-F. (2006). A flow theory perspective on learner motivation and behavior in distance education. Distance Education, 27(1), 45-62.

Martens, R., Bastiaens, T., \& Kirschner, P. A. (2007). New learning design in distance education: The impact on student perception and motivation. Distance Education, 28(1), 81-93.

McCann, E., \& Turner, J. E. (2004). Increasing student learning through volitional control. Teachers College Record, 106(9), 1695-1714. 
Moore, M. G., \& Kearsley, G. (1996). Distance education: A systems view. Belmont, CA: Wadsworth.

Norman, D. A., \& Shallice, T. (1986). Attention to action. Willed and automatic control of behavior. In R. J. Davidson, G. E. Schwartz \& D. Shapiro (Eds.), Consciousness and selfregulation (pp. 1-18). New York: Plenum Press.

Peters, O. (2002). Distance education in transition: New trends and challenges. Oldenburg: Bibliotheks-und Informationssystem der Universität Oldenburg.

Pintrich, P. R. (1999). Taking control of research on volitional control: Challenges for future theory and research. Learning \& Individual Differences, 11(3), 335-351.

Rhodes, S. D., Bowie, D. A., \& Hergenrather, K. C. (2003). Collecting behavioural data using the World Wide Web: Considerations for researchers. Journal of Epidemiology and Community Health, 57(1), 68-73.

Sankaran, S. R., \& Bui, T. (2001). Impact of learning strategies and motivation on performance: A study in web-based instruction. Journal of Instructional Psychology, 28(3), 191-198.

Schwarzer, R. (2008). Some burning issues in research on health and behavior change. Applied Psychology: An International Review, 57(1), 84-93.

Semmar, Y. (2006). Distance learners and academic achievement: The roles of self-efficacy, selfregulation and motivation. Journal of Adult and Continunig Education, 12(2), 244-256.

Sniehotta, F. F., Scholz, U., \& Schwarzer, R. (2005). Bridging the intention-behaviour gap: Planning, self-efficacy, and action control in the adoption and maintenance of physical exercise. Psychology and Health, 20(2), 143-160.

Song, S. H. (2000). Research issues of motivation in web-based instruction. Quarterly Review of Distance Education, 1(3), 225-229.

Thiede, K. W., Anderson, M. C., \& Therriault, D. (2003). Accuracy of metacognitive monitoring affects learning of texts. Journal of Educational Psychology, 95(1), 66-73.

Tinto, V. (1975). Dropout from higher education: A theoretical synthesis of recent research. Review of Educational Research, 45(1), 89-125.

Tuckman, B. W. (2007). The effect of motivational scaffolding on procrastinators' distance learning outcomes. Computers and Education, 49(2), 414-422. 
Wang, Y., Peng, H., Huang, R., Hou, Y., \& Wang, J. (2008). Characteristics of distance learners: Research on relationships of learning motivation, learning strategy, self-efficacy, attribution and learning results. Open Learning: The Journal of Open and Distance Learning, 23(1), 17-28.

Whipp, J. L., \& Chiarelli, S. (2004). Self-regulation in a web-based course: A case study. Educational Technology Research and Development, 52(4), 5-22.

Wickramanayake, D., Schlosser, C., \& Deimann, M. (2008). A comparison of group and individualized motivational messages sent by SMS and e-mail to improve student achievement. In J. Zumbach, N. Schwartz, T. Seufert \& L. Kester (Eds.), Beyond knowledge: The legacy of competence. Meaningful computer-based learning enviornments (pp. 113-115). Berlin: Springer.

Wolters, C. (2003). Understanding procrastination from a self-regulated learning perspective. Journal of Educational Psychology, 95(1), 179-187.

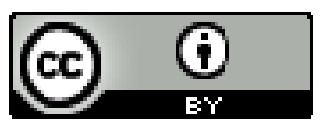

